\title{
Pengaruh Pencucian Benih dengan Penambahan Fungisida Terhadap Tingkat Serangan Penyakit Bulai, Pertumbuhan, dan Hasil Jagung Hibrida Varietas P27
}

\author{
Fai Rachman'1), Ellen Rosyelina Sasmita2), Suyadi Wongsowijoyo2)
}

\begin{abstract}
Corn is an important food crop in the world. Downy mildew as a corn main disease causes a decrease of crop yields. Downy mildew can be prevented by seed treatment. The study aims to determine the effect of washing and adding fungicides on seeds to downy mildew attack, growth, and hybrid corn yields. The research conducted in Wedomartani Experimental Field, Ngemplak, Sleman with experiment in June - October 2018. Field experiment with Randomized Complete Block Design (RCBD) was set up, using single factor, which is seeds of P27 variety washed and added fungicides. There are 10 treatments: control, washed seeds, washed seeds + fungicide metalaxyl $3 \mathrm{~g} / \mathrm{kg}+$ dimetomorph $2 \mathrm{~g} / \mathrm{kg}$, washed seeds + fungicide metalaxyl $3 \mathrm{~g} / \mathrm{kg}+$ dimetomorph $3 \mathrm{~g} / \mathrm{kg}$, washed seeds + fungicide metalaxyl $3 \mathrm{~g} / \mathrm{kg}+$ dimetomorph $4 \mathrm{~g} / \mathrm{kg}$, washed seeds + fungicide metalaxyl $3 \mathrm{~g} / \mathrm{kg}+$ dimetomorph $5 \mathrm{~g} / \mathrm{kg}$, washed seeds + fungicide metalaxyl $5 \mathrm{~g} / \mathrm{kg}$ + dimetomorph $2 \mathrm{~g} / \mathrm{kg}$, washed seeds + fungicide metalaxyl $5 \mathrm{~g} / \mathrm{kg}$ + dimetomorph $3 \mathrm{~g} / \mathrm{kg}$, washed seeds + fungicide metalaxyl $5 \mathrm{~g} / \mathrm{kg}$ + dimetomorph $4 \mathrm{~g} / \mathrm{kg}$, washed seeds + fungicide metalaxyl $5 \mathrm{~g} / \mathrm{kg}$ + dimetomorph $5 \mathrm{~g} / \mathrm{kg}$. The results showed that control effective to prevent downy mildew attack, increasing growth and hybrid corn yields. Washed seeds cause high level of downy mildew attack, slow growth, and low crop yields. Seed treatments with fungicides is not effective, because give same affect with control.
\end{abstract}

Keywords: Corn, Downy Mildew, Fungicide, Seed Treatment

\section{PENDAHULUAN}

Jagung (Zea mays L.) merupakan salah satu tanaman serealia yang tumbuh hampir di seluruh dunia dan tergolong spesies dengan variabilitas genetik yang besar. Jagung termasuk komoditas unggul dibandingkan komoditas pangan lain. Kandungan kimia jagung terdiri atas air $13,5 \%$; protein $10 \%$; lemak $4 \%$; karbohidrat $61 \%$; gula $1,4 \%$; pentosa $6 \%$; serat kasar $2,3 \%$; abu $1,4 \%$; dan zat-zat kimia lainnya $0,4 \%$ (Habib, 2013). Produksi jagung di Indonesia pada tahun 2016 mencapai 23,58 juta ton, dengan produktivitas 5,31 ton/ha (BPS, 2017). Pemerintah sampai saat ini masih melakukan impor jagung untuk memenuhi kebutuhan dalam negeri.

Salah satu kendala dalam meningkatkan hasil jagung adalah penyakit bulai. Penyakit bulai disebabkan oleh jamur Peronosclerospora maydis merupakan penyakit utama jagung yang paling berbahaya di Indonesia. Kerusakan akibat penyakit bulai pada jagung dapat mencapai 90\% (Semangun, 2004 cit., Sekarsari et al., 2013). Gejala tanaman jagung yang terserang bulai adalah daun mengalami klorosis, pertumbuhan lambat, kerdil, sehingga menjadi tidak produktif. Penyebaran penyakit secara alami terjadi melalui media angin dan air.

Varietas P27 memiliki potensi hasil tinggi, namun rentan terhadap serangan bulai (Tias, 2017). Meskipun benih jagung yang dijual di pasaran telah diberi perlakuan benih, namun belum efektif mengatasi penyakit bulai. Oleh karena itu, penelitian diperlukan untuk menentukan efektifitas fungisida dengan bahan aktif lainnya dalam mencegah penyakit bulai pada jagung. Benih jagung di pasaran umumnya sudah diberi

\footnotetext{
1) Mahasiswa Agroteknologi Fak. Pertanian UPN

"Veteran" Yogyakarta

2) Dosen Fak. Pertanian UPN “Veteran” Yogyakarta
}

Author contact: fairachman99@gmail.com perlakuan (seed treatment) fungisida. Tujuan untuk mencegah tanaman terserang penyakit yang disebabkan oleh jamur. Fungisida pada benih dapat dihilangkan dengan cara mencuci benih menggunakan air dan sabun (bleach) hingga bersih. Jagung yang tidak diberi perlakuan benih (seed treatment) dengan fungisida akan lebih mudah terserang penyakit bulai.

Upaya dalam pengendalian penyakit bulai pada jagung yang paling efektif selama ini adalah perlakuan benih dengan fungisida berbahan aktif metalaksil. Namun akhir-akhir ini efektifitas fungisida tersebut sudah mulai berkurang (Muis et al., 2013), oleh karena itu= diperlukan penelitian dengan bahan aktif lain dikombinasikan dengan metalaksil dalam pengendalian penyakit bulai pada jagung. Salah satu bahan aktif fungisida yang dapat mengendalikan penyakit bulai adalah dimetomorf. Tujuan penelitian adalah untuk menentukan pengaruh pencucian benih dan penambahan fungisida terhadap tingkat serangan penyakit bulai, pertumbuhan, dan hasil jagung hibrida.

\section{METODE PENELITIAN}

Penelitian dengan percobaan dilaksanakan di Kebun Percobaan Wedomartani, Ngemplak, Sleman, Daerah Istimewa Yogyakarta pada bulan Juni - Oktober 2018. Lokasi penelitian berada pada ketinggian sekitar +150 m dpl. Percobaan menggunakan Rancangan Acak Kelompok Lengkap (RAKL) faktor tunggal. Faktor perlakuan terdiri atas 10 aras, yaitu kontrol, benih dicuci, benih dicuci + fungisida metalaksil $3 \mathrm{~g} / \mathrm{kg}+$ dimetomorf $2 \mathrm{~g} / \mathrm{kg}$, benih dicuci + fungisida metalaksil $3 \mathrm{~g} / \mathrm{kg}+$ dimetomorf $3 \mathrm{~g} / \mathrm{kg}$, benih dicuci + fungisida metalaksil $3 \mathrm{~g} / \mathrm{kg}+$ dimetomorf $4 \mathrm{~g} / \mathrm{kg}$, benih dicuci + fungisida metalaksil $3 \mathrm{~g} / \mathrm{kg}+$ dimetomorf $5 \mathrm{~g} / \mathrm{kg}$, benih dicuci + fungisida metalaksil $5 \mathrm{~g} / \mathrm{kg}+$ dimetomorf $2 \mathrm{~g} / \mathrm{kg}$, benih dicuci + fungisida metalaksil $5 \mathrm{~g} / \mathrm{kg}$ + dimetomorf $3 \mathrm{~g} / \mathrm{kg}$, 
benih dicuci + fungisida metalaksil $5 \mathrm{~g} / \mathrm{kg}$ + dimetomorf $4 \mathrm{~g} / \mathrm{kg}$, dan benih dicuci + fungisida metalaksil $5 \mathrm{~g} / \mathrm{kg}+$ dimetomorf $5 \mathrm{~g} / \mathrm{kg}$. Setiap perlakuan diulang $3 \mathrm{kali}$, sehingga terdapat 30 petak percobaan masing-masing berukuran 2,4 x $6 \mathrm{~m}$ dengan jarak tanam $20 \times 60 \mathrm{~cm}$ Jumlah populasi per petak adalah 120 tanaman.

Benih yang digunakan merupakan benih varietas P27 yang beredar di pasaran. Benih tersebut sudah mendapatkan perlakuan fungisida dari produsen. Jenis dan konsentrasi fungisida yang digunakan produsen dirahasiakan. Pencucian benih menggunakan bleach dilakukan untuk menghilangkan fungisida bawaan produsen. Setelah benih dicuci, selanjutnya ditambahkan fungisida metalaksil + dimetomorf dengan berbagai konsentrasi. Penanaman dilakukan dengan sistem tanam benih langsung, setiap lubang tanam diisi 2 benih. Pada umur 10 HST, dilakukan penjarangan dengan menyisakan 1 bibit setiap lubang tanam. Pemupukan susulan dilakukan 2 kali, pada umur 25 HST dilakukan pemupukan susulan menggunakan pupuk Urea. Pada umur 45 HST menggunakan pupuk NPK. Dosis setiap pemupukan susulan adalah $150 \mathrm{~kg} / \mathrm{ha}$. Pada umur 15 MST, jagung sudah mencapai masak fisiologis dan dapat dipanen. Tongkol jagung kemudian dikeringkan sampai kadar air $13 \%$ (pengukuran menggunakan grain moisture tester). Setelah kering, kemudian dilakukan pemipilan.

Inokulasi penyakit bulai dilakukan dengan cara menyemprotkan spora bulai pada seluruh tanaman jagung. Spora bulai diperoleh dari jagung umur $2-4$ minggu yang telah terserang penyakit bulai. Tanaman

\section{HASIL DAN PEMBAHASAN}

Tabel 1 Benih tanpa perlakuan, dicuci dengan bleach, dicuci dengan metalaksil dan dimetomorf pada berbagai konsentrasi tidak berpengaruh nyata terhadap persentase tanaman terserang penyakit bulai hingga umur 6 minggu. Pengaruh nyata pencucian baru tampak saat jagung berumur 7 minggu, tetapi persentase serangan terbesar hanya terjadi pada tanaman dari sumber inokulum selanjutnya direndam dalam air selama 8 jam dalam kondisi gelap. Setelah perendaman selama 8 jam, selanjutnya spora dipanen dengan cara menggosok daun yang terserang bulai di dalam air menggunakan tangan. Air yang mengandung spora bulai kemudian disemprotkan ke pucuk tanaman jagung pada pukul 02.00 - 04.00 dini hari. Volume semprot yang digunakan adalah $\pm 1 \mathrm{ml}$ per tanaman.

Pengamatan persentase tanaman terserang penyakit bulai dilakukan dengan menghitung jumlah tanaman terserang penyakit bulai dibagi dengan jumlah tanaman pada petak sampel (48 tanaman yang berada di tengah). Berat tongkol panen (diukur menggunakan timbangan), dan berat biji pipilan (diukur menggunakan timbangan) dilakukan terhadap hasil panen dari petak sampel. Pengamatan daya kecambah dilakukan terhadap seluruh populasi. Pengamatan tinggi tanaman (diukur menggunakan meteran dari permukaan tanah sampai ujung tertinggi daun), diameter tongkol (diukur menggunakan jangka sorong di bagian tengah tongkol), panjang tongkol (diukur menggunakan mistar dari pangkal sampai ujung tongkol), jumlah baris tiap tongkol, dan berat 1000 biji (diukur menggunakan timbangan) dilakukan pada 14 tanaman sampel setiap petak yang dipilih secara acak (simple random sampling). Data yang diperoleh dianalisis dengan menggunakan analisis of varian (ANOVA) $\alpha 5 \%$. Apabila berpengaruh nyata, dilanjutkan menggunakan uji LSD (Least Significant Different) pada taraf $5 \%$.

benih yang dicuci bleach. Ini menunjukkan bahwa ketahanan jagung varietas $\mathrm{P} 27$ relatif tinggi karena tanaman dari benih kontrol persentase serangan hanya $2,78 \%$ tidak berbeda nyata dengan tanaman dari benih yang dicuci pestisida. Hal ini berarti fungisida bawaan dari produsen efektif untuk mengatasi serangan penyakit bulai.

Tabel 1. Pengaruh pencucian benih terhadap persentase tanaman terserang penyakit bulai (\%)

\begin{tabular}{|c|c|c|c|c|}
\hline \multirow{2}{*}{ Konsentrasi fungisida (g/kg) } & \multicolumn{4}{|c|}{ Persentase tanaman terserang penyakit bulai (\%) pada umur (MST) } \\
\hline & 4 & 5 & 6 & 7 \\
\hline Kontrol & $0,00 \mathrm{a}$ & 0,69 a & $2,08 \mathrm{a}$ & $2,78 \mathrm{bc}$ \\
\hline benih dicuci (BC) & $3,47 \mathrm{a}$ & $6,25 \mathrm{a}$ & $13,20 \mathrm{a}$ & $15,97 \mathrm{a}$ \\
\hline $\mathrm{BC}+$ met $3+\operatorname{dimet} 2$ & $0,69 \mathrm{a}$ & 1,39 a & $2,08 \mathrm{a}$ & $2,08 \mathrm{bc}$ \\
\hline $\mathrm{BC}+$ met $3+\operatorname{dimet} 3$ & $0,00 \mathrm{a}$ & 1,39 a & 1,39 a & $2,08 \mathrm{bc}$ \\
\hline $\mathrm{BC}+$ met $3+$ dimet 4 & $0,00 \mathrm{a}$ & $0,69 \mathrm{a}$ & $2,08 \mathrm{a}$ & $2,78 \mathrm{bc}$ \\
\hline $\mathrm{BC}+$ met $3+\operatorname{dimet} 5$ & $1,39 a$ & $4,86 a$ & $6,94 \mathrm{a}$ & $8,33 \mathrm{abc}$ \\
\hline $\mathrm{BC}+$ met $5+\operatorname{dimet} 2$ & $0,69 a$ & $4,17 \mathrm{a}$ & $8,33 \mathrm{a}$ & $9,72 a b$ \\
\hline $\mathrm{BC}+$ met $5+\operatorname{dimet} 3$ & $0,00 \mathrm{a}$ & $0,00 \mathrm{a}$ & $0,69 \mathrm{a}$ & $0,69 \mathrm{c}$ \\
\hline $\mathrm{BC}+\operatorname{met} 5+\operatorname{dimet} 4$ & $0,69 a$ & $3,47 \mathrm{a}$ & $4,86 \mathrm{a}$ & $6,95 \mathrm{bc}$ \\
\hline $\mathrm{BC}+\operatorname{met} 5+\operatorname{dimet} 5$ & $0,00 \mathrm{a}$ & $0,69 \mathrm{a}$ & $3,47 \mathrm{a}$ & $4,17 \mathrm{bc}$ \\
\hline
\end{tabular}

Keterangan: Angka yang diikuti huruf sama pada satu kolom menunjukkan tidak berbeda nyata pada Uji Beda Nyata Terkecil ( $L S D)$ taraf 5\%. MST: minggu setelah tanam, met: metalaksil, dimet: dimetomorf.

Benih tanpa perlakuan, dicuci dengan bleach, dicuci dengan metalaksil dan dimetomorf pada berbagai konsentrasi berpengaruh nyata terhadap daya kecambah umur 7 dan 10 HST. Daya kecambah pada kontrol lebih tinggi daripada perlakuan lain. Kontrol menggunakan benih jagung varietas P27 yang telah 
mendapatkan seed treatment dari produsen. Benih pada kontrol tidak dicuci. Pada perlakuan lain, benih dicuci menggunakan bleach dan fungisida metalaksil + dimetomorf. Hal ini menunjukkan bahwa perlakuan benih dari produsen efektif meningkatkan daya kecambah.

Tabel 2. Pengaruh pencucian benih terhadap daya kecambah (\%)

\begin{tabular}{|c|c|c|}
\hline \multirow{2}{*}{ Konsentrasi fungisida $(\mathrm{g} / \mathrm{kg})$} & \multicolumn{2}{|c|}{ Daya kecambah (\%) pada umur (HST) } \\
\hline & 7 & 10 \\
\hline Kontrol & $87,50 \mathrm{a}$ & $88,47 \mathrm{a}$ \\
\hline benih dicuci (BC) & $80,84 \mathrm{bcd}$ & $82,22 \mathrm{bc}$ \\
\hline$B C+$ met $3+\operatorname{dimet} 2$ & $78,61 \mathrm{~cd}$ & $82,64 \mathrm{bc}$ \\
\hline $\mathrm{BC}+$ met $3+\operatorname{dimet} 3$ & $80,97 \mathrm{bcd}$ & $82,78 \mathrm{bc}$ \\
\hline $\mathrm{BC}+$ met $3+\operatorname{dimet} 4$ & $77,50 \mathrm{~cd}$ & $81,39 \mathrm{bc}$ \\
\hline$B C+$ met $3+\operatorname{dimet} 5$ & $81,94 \mathrm{bc}$ & $82,78 \mathrm{bc}$ \\
\hline $\mathrm{BC}+\operatorname{met} 5+\operatorname{dimet} 2$ & $79,03 \mathrm{bcd}$ & $82,78 \mathrm{bc}$ \\
\hline$B C+\operatorname{met} 5+\operatorname{dimet} 3$ & $83,75 a b$ & $84,86 \mathrm{ab}$ \\
\hline $\mathrm{BC}+\operatorname{met} 5+\operatorname{dimet} 4$ & $76,94 \mathrm{~d}$ & $80,28 \mathrm{c}$ \\
\hline $\mathrm{BC}+$ met $5+\operatorname{dimet} 5$ & 79,72 bcd & $81,81 \mathrm{bc}$ \\
\hline
\end{tabular}

Keterangan: Angka yang diikuti huruf sama pada satu kolom menunjukkan tidak berbeda nyata

Benih tanpa perlakuan, dicuci dengan bleach, dicuci dengan metalaksil dan dimetomorf pada berbagai konsentrasi berpengaruh nyata terhadap tinggi tanaman. Hasil terbaik diperoleh pada perlakuan benih dicuci + fungisida metalaksil $5 \mathrm{~g} / \mathrm{kg}$ + dimetomorf $2 \mathrm{~g} / \mathrm{kg}$. Hal ini sesuai dengan penelitian Burhanuddin (2013) bahwa dosis metalaksil $5 \mathrm{gr} / \mathrm{kg}$ efektif mengatasi penyakit bulai yang menghambat pertumbuhan tanaman jagung, dan penelitian Widiantini et al., (2017) yang menyatakan dosis dimetomorf $2 \mathrm{gr} / \mathrm{kg}$ mampu mencegah pertumbuhan spora penyebab bulai. Dengan serangan penyakit bulai yang rendah, tanaman dapat tumbuh lebih optimal.

Tabel 3. Pengaruh pencucian benih terhadap tinggi tanaman (cm)

\begin{tabular}{lccccc}
\hline \multirow{2}{*}{ Konsentrasi fungisida $(\mathrm{g} / \mathrm{kg})$} & \multicolumn{5}{c}{ Tinggi tanaman $(\mathrm{cm})$ pada umur $(\mathrm{MST})$} \\
\cline { 2 - 6 } & 2 & 3 & 4 & 5 & 6 \\
\hline Kontrol & $26,20 \mathrm{ab}$ & $50,00 \mathrm{a}$ & $84,53 \mathrm{a}$ & $128,47 \mathrm{ab}$ & $182,53 \mathrm{ab}$ \\
benih dicuci $(\mathrm{BC})$ & $21,80 \mathrm{~d}$ & $42,37 \mathrm{c}$ & $75,20 \mathrm{a}$ & $116,37 \mathrm{c}$ & $168,33 \mathrm{~cd}$ \\
$\mathrm{BC}+$ met 3 + dimet 2 & $24,80 \mathrm{abc}$ & $47,37 \mathrm{abc}$ & $82,63 \mathrm{a}$ & $123,40 \mathrm{abc}$ & $174,07 \mathrm{abcd}$ \\
$\mathrm{BC}+$ met 3 + dimet 3 & $26,13 \mathrm{ab}$ & $46,93 \mathrm{abc}$ & $82,03 \mathrm{a}$ & $126,63 \mathrm{ab}$ & $183,17 \mathrm{ab}$ \\
$\mathrm{BC}+$ met 3 + dimet 4 & $24,87 \mathrm{abc}$ & $47,80 \mathrm{ab}$ & $80,63 \mathrm{a}$ & $121,20 \mathrm{bc}$ & $173,73 \mathrm{abcd}$ \\
$\mathrm{BC}+$ met 3 + dimet 5 & $23,50 \mathrm{bcd}$ & $47,62 \mathrm{ab}$ & $80,13 \mathrm{a}$ & $119,40 \mathrm{bc}$ & $171,60 \mathrm{bcd}$ \\
$\mathrm{BC}+$ met 5 + dimet 2 & $26,53 \mathrm{a}$ & $51,30 \mathrm{a}$ & $87,00 \mathrm{a}$ & $130,67 \mathrm{a}$ & $185,20 \mathrm{a}$ \\
$\mathrm{BC}+$ met 5 + dimet 3 & $25,30 \mathrm{abc}$ & $47,53 \mathrm{ab}$ & $81,13 \mathrm{a}$ & $122,87 \mathrm{abc}$ & $177,03 \mathrm{abc}$ \\
$\mathrm{BC}+$ met 5 + dimet 4 & $22,83 \mathrm{~cd}$ & $42,93 \mathrm{bc}$ & $76,47 \mathrm{a}$ & $115,50 \mathrm{c}$ & $164,40 \mathrm{~d}$ \\
$\mathrm{BC}+$ met 5 + dimet 5 & $25,73 \mathrm{abc}$ & $47,10 \mathrm{abc}$ & $81,63 \mathrm{a}$ & $125,50 \mathrm{ab}$ & $176,70 \mathrm{abcd}$ \\
\hline
\end{tabular}

Keterangan: Angka yang diikuti huruf sama pada satu kolom menunjukkan tidak berbeda nyata pada Uji Beda Nyata Terkecil (LSD) taraf 5\%. MST: minggu setelah tanam, met: metalaksil, dimet: dimetomorf.

Benih tanpa perlakuan, dicuci dengan bleach, dicuci dengan metalaksil dan dimetomorf pada berbagai konsentrasi berpengaruh nyata terhadap diameter tongkol. Diameter tongkol pada kontrol berbeda nyata dengan benih dicuci dan benih dicuci + fungisida metalaksil $5 \mathrm{~g} / \mathrm{kg}+$ dimetomorf $4 \mathrm{~g} / \mathrm{kg}$. Hal ini karena konsentrasi fungisida pada perlakuan benih dicuci + fungisida metalaksil $5 \mathrm{~g} / \mathrm{kg}$ + dimetomorf $4 \mathrm{~g} / \mathrm{kg}$ terlalu tinggi, sehingga memberikan pengaruh negatif pada tanaman. Konsentrasi fungisida yang terlalu tinggi dapat mengakibatkan kerusakan pada tanaman. Menurut Irawan et al., (2015), fungisida sintetik dengan konsentrasi tinggi dapat berdampak negatif bagi tanaman, yaitu terjadinya fitotoksisitas (keracunan tanaman).

Tabel 4. Pengaruh pencucian benih terhadap diameter tongkol (mm)

\begin{tabular}{lc}
\hline $\begin{array}{c}\text { Konsentrasi fungisida } \\
(\mathrm{g} / \mathrm{kg})\end{array}$ & $\begin{array}{c}\text { Diameter tongkol } \\
(\mathrm{mm})\end{array}$ \\
\hline kontrol & $45,52 \mathrm{a}$ \\
benih dicuci $(\mathrm{BC})$ & $36,84 \mathrm{bc}$ \\
$\mathrm{BC}+$ met 3 + dimet 2 & $44,26 \mathrm{a}$ \\
$\mathrm{BC}+$ met 3 + dimet 3 & $46,63 \mathrm{a}$ \\
$\mathrm{BC}+$ met 3 + dimet 4 & $45,09 \mathrm{a}$ \\
$\mathrm{BC}+$ met 3 + dimet 5 & $43,63 \mathrm{ab}$
\end{tabular}




\begin{tabular}{cc}
\hline $\begin{array}{c}\text { Konsentrasi fungisida } \\
(\mathrm{g} / \mathrm{kg})\end{array}$ & $\begin{array}{c}\text { Diameter tongkol } \\
(\mathrm{mm})\end{array}$ \\
\hline $\mathrm{BC}+$ met $5+$ dimet 2 & $45,09 \mathrm{a}$ \\
$\mathrm{BC}+$ met 5 + dimet 3 & $45,73 \mathrm{a}$ \\
$\mathrm{BC}+$ met 5 + dimet 4 & $35,69 \mathrm{c}$ \\
$\mathrm{BC}+$ met 5 + dimet 5 & $41,93 \mathrm{abc}$
\end{tabular}

Keterangan: Angka yang diikuti huruf sama pada satu kolom menunjukkan tidak berbeda nyata pada Uji Beda Nyata Terkecil.

Benih tanpa perlakuan, dicuci dengan bleach, dicuci dengan metalaksil dan dimetomorf pada berbagai konsentrasi tidak berpengaruh nyata terhadap panjang tongkol. Hal ini karena pengaruh pupuk susulan yang diberikan dalam dosis yang sama, sehingga unsur hara yang dibutuhkan tanaman dalam pembentukan tongkol berada dalam jumlah yang relatif sama. Menurut Novira et al., (2015), panjang tongkol jagung lebih dipengaruhi oleh faktor genetik, sedangkan kemampuan tanaman untuk memunculkan karakter genetiknya dipengaruhi oleh faktor lingkungan.

Tabel 5. Pengaruh pencucian benih terhadap panjang tongkol $(\mathrm{cm})$

\begin{tabular}{lc}
\hline Konsentrasi fungisida $(\mathrm{g} / \mathrm{kg})$ & Panjang tongkol $(\mathrm{cm})$ \\
\hline kontrol & $15,56 \mathrm{a}$ \\
benih dicuci $(\mathrm{BC})$ & $12,72 \mathrm{a}$ \\
$\mathrm{BC}+$ met $3+$ dimet 2 & $14,70 \mathrm{a}$ \\
$\mathrm{BC}+$ met $3+$ dimet 3 & $15,55 \mathrm{a}$ \\
$\mathrm{BC}+$ met 3 + dimet 4 & $15,32 \mathrm{a}$ \\
$\mathrm{BC}+$ met 3 + dimet 5 & $14,78 \mathrm{a}$ \\
$\mathrm{BC}+$ met 5 + dimet 2 & $15,19 \mathrm{a}$ \\
$\mathrm{BC}+$ met 5 + dimet 3 & $15,11 \mathrm{a}$ \\
$\mathrm{BC}+$ met 5 + dimet 4 & $12,27 \mathrm{a}$ \\
$\mathrm{BC}+$ met 5 + dimet 5 & $14,37 \mathrm{a}$ \\
\hline
\end{tabular}

Keterangan: Angka yang diikuti huruf sama pada satu kolom menunjukkan tidak berbeda nyata pada Uji Beda Nyata Terkecil $(L S D)$.

Benih tanpa perlakuan, dicuci dengan bleach, dicuci dengan metalaksil dan dimetomorf pada berbagai konsentrasi berpengaruh nyata terhadap jumlah baris tiap tongkol. Jumlah baris tiap tongkol tertinggi terdapat pada perlakuan benih dicuci + fungisida metalaksil $3 \mathrm{~g} / \mathrm{kg}+$ dimetomorf $3 \mathrm{~g} / \mathrm{kg}$ dan benih dicuci + fungisida metalaksil $5 \mathrm{~g} / \mathrm{kg}+$ dimetomorf $2 \mathrm{~g} / \mathrm{kg}$. Namun keduanya tidak berbeda nyata dengan kontrol. Hal ini menunjukkan bahwa perlakuan benih dari produsen cukup efektif, karena mampu menghasilkan tongkol dengan jumlah baris yang tinggi.

Tabel 6. Pengaruh pencucian benih terhadap jumlah baris tiap tongkol (baris)

\begin{tabular}{lc}
\hline $\begin{array}{c}\text { Konsentrasi fungisida } \\
(\mathrm{g} / \mathrm{kg})\end{array}$ & $\begin{array}{c}\text { Jumlah baris tiap tongkol } \\
\text { (baris) }\end{array}$ \\
\hline Kontrol & $14,74 \mathrm{ab}$ \\
benih dicuci (BC) & $12,98 \mathrm{bc}$ \\
$\mathrm{BC}+$ met 3 + dimet 2 & $14,81 \mathrm{ab}$
\end{tabular}

\begin{tabular}{cc}
\hline $\begin{array}{c}\text { Konsentrasi fungisida } \\
(\mathrm{g} / \mathrm{kg})\end{array}$ & $\begin{array}{c}\text { Jumlah baris tiap tongkol } \\
\text { (baris) }\end{array}$ \\
\hline $\mathrm{BC}+$ met $3+\operatorname{dimet} 3$ & $15,76 \mathrm{a}$ \\
$\mathrm{BC}+$ met $3+\operatorname{dimet} 4$ & $15,14 \mathrm{ab}$ \\
$\mathrm{BC}+$ met $3+\operatorname{dimet} 5$ & $14,67 \mathrm{ab}$ \\
$\mathrm{BC}+$ met $5+\operatorname{dimet} 2$ & $15,81 \mathrm{a}$ \\
$\mathrm{BC}+$ met $5+\operatorname{dimet} 3$ & $14,90 \mathrm{ab}$ \\
$\mathrm{BC}+$ met $5+\operatorname{dimet} 4$ & $11,74 \mathrm{c}$ \\
$\mathrm{BC}+$ met $5+\operatorname{dimet} 5$ & $14,43 \mathrm{ab}$ \\
\hline
\end{tabular}

Keterangan: Angka yang diikuti huruf sama pada satu kolom menunjukkan tidak berbeda nyata pada Uji Beda Nyata Terkecil.

Benih tanpa perlakuan, dicuci dengan bleach, dicuci dengan metalaksil dan dimetomorf pada berbagai konsentrasi tidak berpengaruh nyata terhadap berat tongkol panen dan berat biji pipilan. Hal ini karena pengaruh pupuk susulan yang diberikan dalam dosis yang sama, sehingga unsur hara yang dibutuhkan tanaman dalam pembentukan tongkol berada dalam jumlah yang relatif sama.

Tabel 7. Pengaruh pencucian benih terhadap berat tongkol panen tanpa kelobot (ton/ha) dan berat biji pipilan (ton/ha)

\begin{tabular}{lcc}
\hline $\begin{array}{c}\text { Konsentrasi } \\
\text { fungisida }(\mathrm{g} / \mathrm{kg})\end{array}$ & $\begin{array}{c}\text { Berat tongkol } \\
\text { panen (ton/ha) }\end{array}$ & $\begin{array}{c}\text { Berat biji } \\
\text { pipilan } \\
\text { (ton/ha) }\end{array}$ \\
\hline kontrol & $16,78 \mathrm{a}$ & $9,48 \mathrm{a}$ \\
benih dicuci $(\mathrm{BC})$ & $15,16 \mathrm{a}$ & $8,32 \mathrm{a}$ \\
$\mathrm{BC}+$ met $3+$ dimet 2 & $18,17 \mathrm{a}$ & $10,28 \mathrm{a}$ \\
$\mathrm{BC}+$ met 3 + dimet 3 & $17,78 \mathrm{a}$ & $9,82 \mathrm{a}$ \\
$\mathrm{BC}+$ met 3 + dimet 4 & $17,62 \mathrm{a}$ & $9,85 \mathrm{a}$ \\
$\mathrm{BC}+$ met 3 + dimet 5 & $16,62 \mathrm{a}$ & $9,12 \mathrm{a}$ \\
$\mathrm{BC}+$ met 5 + dimet 2 & $16,25 \mathrm{a}$ & $8,66 \mathrm{a}$ \\
$\mathrm{BC}+$ met 5 + dimet 3 & $18,47 \mathrm{a}$ & $10,56 \mathrm{a}$ \\
$\mathrm{BC}+$ met 5 + dimet 4 & $15,78 \mathrm{a}$ & $8,90 \mathrm{a}$ \\
$\mathrm{BC}+$ met 5 + dimet 5 & $16,96 \mathrm{a}$ & $9,82 \mathrm{a}$ \\
\hline Keterangan:
\end{tabular}

Keterangan: Angka yang diikuti huruf sama pada satu kolom menunjukkan tidak berbeda nyata pada Uji Beda Nyata Terkecil.

Benih tanpa perlakuan, dicuci dengan bleach, dicuci dengan metalaksil dan dimetomorf pada berbagai konsentrasi berpengaruh nyata terhadap berat 1000 biji. Benih dicuci memiliki berat 1000 biji yang lebih rendah daripada perlakuan lainnya. Hal ini karena benih tidak diperlakukan ulang dengan fungisida sehingga tanaman lebih mudah terserang penyakit. Tanaman yang terserang penyakit bulai umumnya tidak dapat menghasilkan tongkol normal. Hal ini sesuai dengan penelitian Daryono et al., (2018) yang menyatakan bahwa tongkol jagung pada tanaman terinfeksi bulai tidak terbentuk secara sempurna. Menurut Raissa (2017), apabila infeksi bulai terjadi pada tanaman yang sudah berumur satu bulan, tanaman masih bisa tetap tumbuh dan berbuah namun tongkolnya tidak besar. 
Selain itu kelobot tidak bisa membungkus secara penuh pada tongkol dan bijinya tidak terisi penuh.

Tabel 8. Pengaruh pencucian benih terhadap berat 1000 biji (gr)

\begin{tabular}{|c|c|}
\hline Konsentrasi fungisida $(\mathrm{g} / \mathrm{kg})$ & Berat 1000 biji (gr \\
\hline kontrol & $267,67 \mathrm{a}$ \\
\hline benih dicuci (BC) & $240,00 \mathrm{~b}$ \\
\hline BC + met $3+$ dimet 2 & $261,00 \mathrm{a}$ \\
\hline $\mathrm{BC}+\operatorname{met} 3+\operatorname{dimet} 3$ & $259,33 a$ \\
\hline $\mathrm{BC}+$ met $3+\operatorname{dimet} 4$ & $259,00 \mathrm{a}$ \\
\hline $\mathrm{BC}+$ met $3+\operatorname{dimet} 5$ & $258,67 \mathrm{a}$ \\
\hline $\mathrm{BC}+$ met $5+\operatorname{dimet} 2$ & $258,33 a$ \\
\hline $\mathrm{BC}+$ met $5+\operatorname{dimet} 3$ & $265,33 \mathrm{a}$ \\
\hline $\mathrm{BC}+$ met $5+\operatorname{dimet} 4$ & $263,67 \mathrm{a}$ \\
\hline $\mathrm{BC}+$ met $5+\operatorname{dimet} 5$ & $262,33 \mathrm{a}$ \\
\hline
\end{tabular}

Keterangan: Angka yang diikuti huruf sama pada satu kolom menunjukkan tidak berbeda nyata pada Uji Beda Nyata Terkecil ( $L S D)$ taraf 5\%. met: metalaksil, dimet: dimetomorf.

\section{KESIMPULAN}

Kontrol efektif dalam mencegah serangan penyakit bulai, serta meningkatkan pertumbuhan dan hasil jagung hibrida. Pencucian benih dengan bleach menyebabkan serangan penyakit bulai yang tinggi, pertumbuhan tanaman yang lambat, dan hasil yang lebih rendah. Perlakuan dengan fungisida tidak efektif, karena memberikan pengaruh yang tidak berbeda nyata dengan kontrol.

\section{DAFTAR PUSTAKA}

BPS, 2017, Luas Panen, Hasil Per Hektar, dan Produksi Jagung di Indonesia Tahun 2016 (Angka Tetap 2016), Badan Pusat Statistik.

Burhanuddin, 2013, "Uji Efektifitas Fungisida Saromil 35SD (b.a. Metalaksil) Terhadap Penyakit Bulai (Peronosclerospora philippinensis) Pada Tanaman Jagung", dalam Prosiding Seminar Nasional Inovasi Teknologi Pertanian (Maros, 29 Juli 2013), hal 68 75.

Daryono, B., Purnomo., dan A Parazulfa. 2018, Uji Ketahanan Tujuh Kultivar Jagung (Zea mays L.) Terhadap Penyakit Bulai (Peronosclerospora sp), J Biogenesis, 10(1) : 11- 17.

Habib, A, 2013, Analisis Faktor-Faktor yang Mempengaruhi Produksi Jagung, J Agrium, 18(1): $79-87$.

Irawan, A., Anggraeni, I., dan Christita, M. 2015, Identifikasi Penyebab Penyakit Bercak Daun Pada Bibit Cempaka (Magnolia elegans (Blume) H.Keng) dan Teknik Pengendaliannya, J Wasian, 2(2) : 87 94.

Muis, A., Nonci, N., dan Pabendon, M, B. 2013, "Skrining Galur / Varietas Lokal Jagung Terhadap Penyakit Bulai", dalam Prosiding Seminar Nasional Serealia Tahun 2013 (Maros, 18 Juni 2013), hal 380 - 386.

Novira, F., Husnayetti., dan Yoseva, S. 2015, Pemberian Pupuk Limbah Cair Biogas dan Urea, TSP, KCl Terhadap Pertumbuhan dan Produksi Tanaman
Jagung Manis (Zea mays saccharata Sturt.), J Jom Faperta, 2(1) : 1 - 15.

Raissa, D, 2017, Pengaruh Aplikasi Beberapa Jenis Fungisida Melalui Teknik Perlakuan Benih Terhadap Insiden Penyakit Bulai Jagung (Peronosclerospora sp), [skripsi], Jurusan Agroteknologi Fakultas Pertanian Universitas Negeri Lampung, 39 hal.

Sekarsari, R, A., Prasetyo, J., dan Maryono, T. 2013, Pengaruh Beberapa Fungisida Nabati Terhadap Keterjadian Penyakit Bulai Pada Jagung Manis (Zea mays saccharata), J Agrotek Tropika, 1(1) : 98 $-101$.

Tias, D, R, K, 2017, Efikasi Asam Fosfit, Dimetomorf dan Metalaksil Untuk Mengendalikan Penyakit Bulai (Peronosclerospora sorghi) Pada Tanaman Jagung (Zea mays L.) Varietas P27, [skripsi], Universitas Lampung, 44 hal.

Widiantini, F., Pitaloka, D, J., Nasahi, C., dan Yulia, E. 2017, Perkecambahan Peronosclerospora spp Asal Beberapa Daerah di Jawa Barat pada Fungisida Berbahan Aktif Metalaksil, Dimetomorf dan Fenamidon, J Agrikultura, 28(2) : 95 - 102. 